\title{
Breast cancer associated with primary hyperparathyroidism: a nested case control study
}

This article was published in the following Dove Press journal:

Clinical Epidemiology

23 March 20II

Number of times this article has been viewed

\author{
Sophie Norenstedt ${ }^{1,7}$ \\ Fredrik Granath ${ }^{2}$ \\ Anders Ekbom² \\ Jonas Bergh ${ }^{3}$ \\ Mats Lambe 4 \\ Jan Adolfsson ${ }^{5}$ \\ Fredrik Warnberg ${ }^{6}$ \\ Jan Zedenius ${ }^{1,7}$ \\ Inga-Lena Nilsson ${ }^{1,7}$ \\ 'Department of Molecular Medicine \\ and Surgery, ${ }^{2}$ Department of \\ Medicine, ${ }^{3}$ Department of Oncology \\ and Pathology, Karolinska Institutet \\ and Cancer Center Radiumhemmet, \\ Karolinska University Hospital, \\ Stockholm; ${ }^{4}$ Regional Oncology \\ Centre, Uppsala; ${ }^{5}$ Oncologic Center, \\ Karolinska University Hospital and \\ CLINTEC Department, Karolinska \\ Institutet, Stockholm; ${ }^{6}$ Department of \\ Surgery, Uppsala Academic Hospital, \\ Uppsala University; ${ }^{7}$ Endocrine \\ Surgery Unit, Karolinska University \\ Hospital, Stockholm, Sweden
}

Correspondence: Sophie Norenstedt Department of Molecular Medicine and Surgery, Karolinska Institutet, SE I7I 76 Stockholm, Sweden Tel +4685870 1000

Email sophie.norenstedt@ki.se
Background: Primary hyperparathyroidism (pHPT) is associated with an increased risk of developing breast cancer, but little is known about the underlying factors. The aim of this study was to compare women with a history of pHPT and a reference population in terms of standard factors predictive of prognosis and response to therapy for breast cancer.

Methods: We analyzed data collected from the National Swedish Cancer Register and from two regional oncologic center registries. Seventy-one women with breast cancer and a history of parathyroid adenomectomy were compared with 338 matched controls with breast cancer only. Tumor size, stage, hormone receptor status, lymph node status, cause of death, and cumulative survival were analyzed.

Results: The mean age was $69 \pm 11$ years (95\% confidence interval [CI]: 68-70) in both groups and the mean time interval between the parathyroid surgery and breast cancer diagnosis was $91 \pm 68$ months (95\% CI: 72-111). There were no differences between the two groups regarding size, stage, lymph node metastases, or survival, but none of the cases with a history of pHPT were found in Stage III or IV.

Conclusion: In conclusion, factors predictive of prognosis and response to therapy in women with a history of pHPT and breast cancer are similar to those in breast cancer patients without pHPT.

Keywords: breast cancer, primary hyperparathyroidism, prognostic factors

\section{Introduction}

Primary hyperparathyroidism (pHPT) is associated with an increased risk of premature death in malignant disorders. ${ }^{1-3}$ The prevalence of $\mathrm{pHPT}$ is highest in postmenopausal women, ie, $3 \%-4 \%$, and the origin is most often a single parathyroid adenoma. ${ }^{4,5}$ Certain malignant tumors are over-represented, and breast cancer is the most frequent, comprising $25 \%$ of the malignancies diagnosed after parathyroid adenomectomy in women. ${ }^{3,6}$ An increased frequency of parathyroid adenoma and significantly higher serum calcium and parathyroid hormone levels have been documented in patients treated for breast cancer compared with healthy controls. ${ }^{7}$ These findings were unrelated to clinical staging or antitumor therapy. Little is known about the association between pHPT and the development of breast cancer. Causal relationships have been discussed, and various shared predisposing genetic and environmental risk factors have been hypothesized. The aim of this study was to evaluate factors predictive of prognosis and response to therapy in a cohort of breast cancer patients with a history of pHPT and to search for a potential link between pHPT and breast cancer. 


\section{Patients and methods}

We used the National Swedish Cancer Register to select the study population. It is a well-validated register, where underreporting is $3 \%-4 \% .{ }^{8}$ All malignant and a few benign tumors, including parathyroid adenomas, are reported to the register by both the treating physician and the pathologist making the diagnosis. The diagnoses are coded using the International Classification of Diseases 7 th revision (ICD-7). Requisites for inclusion of cases in this study were parathyroid adenomectomy of a single parathyroid adenoma (ICD-7 1951) and a subsequent diagnosis of invasive breast cancer (ICD-7 170). To minimize confounding by diagnosis, we excluded all cases with a breast cancer diagnosis before primary hyperparathyroidism $(n=59)$. All males were excluded, as were all women with a diagnosis of breast carcinoma in situ.

We identified 71 women with breast cancer and previous surgery for pHPT during the period from January 1, 1992 to December 31, 2006. For each patient, five control subjects with breast cancer but no history of parathyroid surgery, matched for age and time period, were enrolled. Using the national registration number, a unique identifier for each Swedish resident made linkage possible to two of Sweden's six regional breast cancer registers. The registers for the Stockholm-Gotland and Uppsala-Örebro regions cover a population of 3.9 million, or $43 \%$ of the Swedish population. Data on tumor size, stage, and hormonal receptor status were retrieved. The American Joint Committee on Cancer staging system for breast cancer was used. ${ }^{9}$ Dates of death until December 31, 2009 and causes of death until December 31, 2008 were retrieved from the Swedish Cause of Death Register. The study was approved by the ethical committee at the Karolinska Institutet, Stockholm, Sweden.

\section{Statistical analysis}

Statistical analysis was performed with the PASW for Windows statistical package (18.0;PASW Inc., Chicago, IL). The Student's two-tailed, unpaired $t$-test was used to compare mean tumor size between the cases and control subjects. The Chi-square test was used to compare lymph node involvement, and receptor status. The distributions of tumor characteristics of cases and controls were compared by Pearson Chi-Square test. When cells had expected counts less than 5, a corresponding exact test was applied. Survival time was calculated as the number of months between the date of diagnosis and date of death, or date at end of follow-up (whichever occurred first). Breast cancer survival is presented in a Kaplan-Meier plot and tested with the logrank test. $P<0.05$ was considered to be statistically significant.

\section{Results}

The mean age at diagnosis of breast cancer was 69 years, with a standard deviation (SD) of 11 years ( $95 \%$ confidence interval [CI]: 68-70) in both groups. The age distribution for the cases and controls is presented in Table 1. The interval between the parathyroid adenoma operation and breast cancer registration ranged from 1 to 292 months (mean 91 months, SD 68 months, 95\% CI: 72-111). Tumor size, stage, axillary lymph node status, and hormone receptor status are presented in Table 2. None of the prognostic factors analyzed in this study differed between the women with and those without a history of pHPT. The duration of follow-up ranged from 0 to 307 months (mean 80 months, SD 59 months, 95\% CI: 74-86). In December 31, 2009, 29 (41\%) cases and $150(44 \%)$ controls had died. There was no statistically significant difference between the two groups in cumulative breast cancer-specific survival (see Figure 1).

\section{Discussion}

The mechanisms underlying the coexistence of pHPT and certain malignancies, including breast cancer, are still unknown. To our knowledge, the prognosis of breast cancer in women with a history of pHPT has not been studied systematically. The aim of our study was to investigate whether the prognosis for breast cancer associated with pHPT differs from that for breast cancer in the background population. Comparing tumor size, stage, hormone receptor status, and the most important prognostic factor, axillary lymph node status, we found no difference between women with and those without a history of pHPT. Remarkably, none of the cases had Stage III or IV disease. Breast cancerspecific survival was the same in the two groups.

Our study design has some limitations. Data on the prognostic factor, and predictive factor for trastuzumab therapy,

Table I Age distribution of women with primary hyperparathyroidism and breast cancer (cases) and women with breast cancer only (controls)

\begin{tabular}{lll}
\hline Age group (years) & $\begin{array}{l}\text { Cases } \\
(\mathbf{n}=\mathbf{7 1})\end{array}$ & $\begin{array}{l}\text { Controls } \\
(\mathbf{n}=\mathbf{3 3 8})\end{array}$ \\
\cline { 2 - 3 } & $(\mathbf{n})$ & $(\mathbf{n})$ \\
\hline $0-49$ & 2 & 10 \\
$50-54$ & 5 & 24 \\
$55-59$ & 8 & 34 \\
$60-64$ & 9 & 43 \\
$65-69$ & 11 & 54 \\
$70-74$ & 9 & 41 \\
$75-79$ & 16 & 77 \\
$80+$ & 11 & 55 \\
\hline
\end{tabular}

Note: Mean age at breast cancer diagnosis (year \pm standard deviation) $69 \pm 1 \mathrm{I}$, $95 \%$ confidence interval $68-70$. 
Table 2 Tumor characteristics in women with pHPT+breast cancer (cases) and women with breast cancer only (controls)

\begin{tabular}{|c|c|c|c|}
\hline & $\begin{array}{l}\text { Cases } \\
(n=7 I)\end{array}$ & $\begin{array}{l}\text { Controls } \\
(n=338)\end{array}$ & $P$-value \\
\hline Tumor size $(\mathrm{mm} \pm \mathrm{SD})$ & $18 \pm 10$ & $20 \pm 14$ & 0.27 \\
\hline Missing & 4 & 29 & \\
\hline \multicolumn{4}{|c|}{ Axillary lymph node status } \\
\hline Negative & $35(59 \%)$ & $176(65 \%)$ & \\
\hline I-3 positive nodes & 11 (19\%) & $63(23 \%)$ & \\
\hline$\geq 4$ positive nodes & $13(22 \%)$ & $32(12 \%)$ & 0.11 \\
\hline Missing & $12(17 \%)$ & $67(20 \%)$ & \\
\hline \multicolumn{4}{|l|}{ Tumor stage } \\
\hline $\mathrm{I}(\mathrm{TI}+\mathrm{N} 0)$ & $29(46 \%)$ & $149(5 \mid \%)$ & \\
\hline Ila $(\mathrm{TI}+\mathrm{NI}$ or $\mathrm{T} 2+\mathrm{N} 0)$ & $25(40 \%)$ & 77 (27\%) & \\
\hline Ilb $(\mathrm{T} 2+\mathrm{NI}$ or $\mathrm{T} 3+\mathrm{N} 0)$ & $9(14 \%)$ & $49(17 \%)$ & \\
\hline III $(\mathrm{T} 3+\mathrm{NI}$ or $\mathrm{T} 4)$ & $0(0 \%)$ & $4(1 \%)$ & \\
\hline IV (MI) & $0(0 \%)$ & II (4\%) & $0.13^{c}$ \\
\hline Undefined & $8(1 / \%)$ & 48 (I4\%) & \\
\hline \multicolumn{4}{|l|}{ Hormone receptor status } \\
\hline Positive $^{a}$ & $46(88 \%)$ & $217(84 \%)$ & \\
\hline Negative $^{b}$ & $6(12 \%)$ & $42(16 \%)$ & 0.38 \\
\hline Missing & $19(27 \%)$ & 79 (23\%) & \\
\hline
\end{tabular}

Notes: aER-positive, P-positive or -negative according to local laboratory and clinical standards. ${ }^{b} E R-$ and PR-negative. ' $E x a c t$ Pearson Chi-Square test

HER-2/neu, were incomplete, and there were no data on the cell proliferation marker, Ki-67. Elston-Ellis tumor grade could not be properly analyzed due to too many missing data, particularly in the earlier periods when the grade was not registered prospectively. Risk factors for breast cancer and data on calcium and vitamin D levels were not available in the registries.

We cannot exclude the presence of pHPT in the control group but, because the prevalence of $\mathrm{pHPT}$ in the population is low, it may affect only isolated cases. ${ }^{5}$

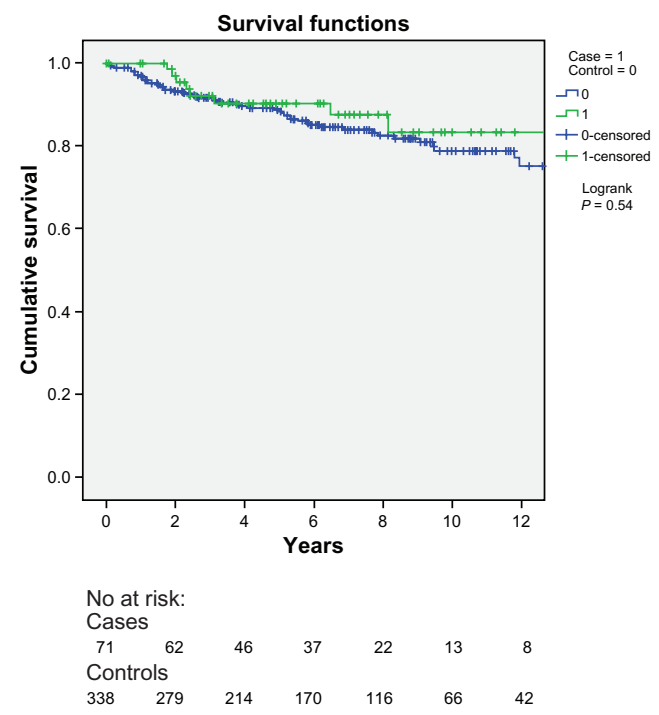

Figure I Kaplan-Meier plots of breast cancer-specific survival in women with pHPT + breast cancer (cases) and women with breast cancer only (controls).
Our study design does not allow for comparisons between different treatment modalities, because the registry does not contain such data. However, the bias induced by differences in treatment strategy is likely to have been negligible, because there was near to complete compliance with regional/national treatment guidelines, and also by matching of five controls per case from the same region.

The strengths of the study are that the registers used are well validated and that two important prognostic factors, ie, tumor size and lymphatic involvement, were included. ${ }^{8,9}$ The risk of confounding by diagnosis was minimized by excluding all cases with a breast cancer diagnosis before the diagnosis of $\mathrm{pHPT}$.

The coexistence of pHPT and breast cancer, recognized in several case reports and confirmed in large population studies, has given rise to much speculation concerning possible etiologic links. ${ }^{1,3,6,7}$ It remains to be elucidated whether the association between $\mathrm{pHPT}$ and breast cancer is due to predisposing genetic or environmental risk factors. Abnormalities in calcium metabolism have been associated with breast cancer risk, but the results reported from different studies have not been consistent. Although higher serum calcium levels have been reported from breast cancer cohorts, no correlation was found between calcium level and tumor stage..$^{710,11}$ A causal relationship between hypercalcemia and malignancy seems unlikely, given that the risk of breast cancer remains unchanged at least 15 years after parathyroid adenomectomy. ${ }^{3}$ Vitamin D may be a key factor, and there is evidence of potential links between vitamin D deficiency and the development and prognosis of breast cancer, as well as aggravated clinical presentation of pHPT and increased parathyroid tumor growth. ${ }^{12-16} \mathrm{~A}$ modestly reduced incidence of breast cancer associated with a higher intake of vitamin D was reported from a meta-analysis of observational studies. ${ }^{17}$ The results from a randomized clinical trial of calcium and vitamin D supplementation versus placebo among postmenopausal women for a mean of seven years showed no detectable effect on breast cancer risk. ${ }^{18}$ However, the supplementation dose was rather low (1000 mg of elemental calcium with $400 \mathrm{IU}$ vitamin $\mathrm{D}_{3}$ daily), additional use of calcium and vitamin D supplements was allowed, and the discontinuation rate was quite high. Comparing data on vitamin D levels from different observational studies is complicated by differences in definitions and diagnostic methods. ${ }^{19}$ Furthermore, many factors may interfere with the interpretation of vitamin D status, such as age, body mass index, liver and kidney function, chronic illness, and sun exposure. ${ }^{19,20}$ Overweight is another reported risk factor that has been coupled with increased risk of postmenopausal breast cancer, pHPT, and vitamin D deficiency. ${ }^{11,21-23}$ 
There has also been speculation about other factors, such as genetic predisposition, that may influence vitamin D levels. Familial accumulation of hyperparathyroidism and breast cancer, as well as isolated cases with high penetrance cancer susceptibility genes, have been reported. ${ }^{24,25}$ Hitherto, exposure to ionizing radiation is the only established risk factor with a confirmed dose-response relationship for both parathyroid adenoma and breast cancer. ${ }^{26,27}$

\section{Conclusion}

In this study, women diagnosed with breast cancer and having an earlier history of pHPT had the same tumor risk factors and the same breast cancer-specific survival as women with breast cancer and no previous history of hyperparathyroidism.

\section{Acknowledgments}

We would like to express our sincere gratitude to the Stockholm-Gotland and Uppsala-Örebro Breast Cancer Groups, Henrik Hellborg at the Oncologic Center in Stockholm, and Marit Holmqvist at the Regional Oncologic Center in Uppsala for their management of the data.

\section{Disclosure}

The authors report no conflicts of interest in this work.

\section{References}

1. Palmer M, Adami HO, Krusemo UB, Ljunghall S. Increased risk of malignant diseases after surgery for primary hyperparathyroidism. A nationwide cohort study. Am J Epidemiol. 1988;127:1031-1040.

2. Pickard AL, Gridley G, Mellemkjæ L, et al. Hyperparathyroidism and subsequent cancer risk in Denmark. Cancer. 2002;95:1611-1617.

3. Nilsson IL, Zedenius J, Yin L, Ekbom A. The association between primary hyperparathyroidism and malignancy: Nationwide cohort analysis on cancer incidence after parathyroidectomy. Endocr Relat Cancer. 2007;14:135-140.

4. Marx SJ. Hyperparathyroid and hypoparathyroid disorders. $N$ Engl J Med. 2000;343:1863-1875.

5. Lundgren E, Hagstrom EG, Lundin J, et al. Primary hyperparathyroidism revisited in menopausal women with serum calcium in the upper normal range at population-based screening 8 years ago. World J Surg. 2002; 26:931-936.

6. Michels KB, Xue F, Brandt L, Ekbom A. Hyperparathyroidism and subsequent incidence of breast cancer. Int J Cancer. 2004;110:449-451.

7. Fierabracci P, Pinchera A, Miccoli P, et al. Increased prevalence of primary hyperparathyroidism in treated breast cancer. $J$ Endocrinol Invest. 2001;24:315-320.

8. Barlow L, Westwrgren K, Holmberg L, Talback M. The completeness of the Swedish Cancer Register: A sample survey for year 1998. Acta Oncol. 2009;48:27-33.

Clinical Epidemiology

\section{Publish your work in this journal}

Clinical Epidemiology is an international, peer-reviewed, open access journal focusing on disease and drug epidemiology, identification of risk factors and screening procedures to develop optimal preventative initiatives and programs. Specific topics include: diagnosis, prognosis, treatment, screening, prevention, risk factor modification, systematic Submit your manuscript here: http://www.dovepress.com/clinical-epidemiology-journal
9. Singletary SE, Allred C, Ashley P, et al. Revision of the American Joint Committee on Cancer staging system for breast cancer. J Clin Oncol. 2002;20:3628-3636.

10. Camacho PM, Dayal AS, Diaz JL, et al. Prevalence of secondary causes of bone loss among breast cancer patients with osteopenia and osteoporosis. J Clin Oncol. 2008;26:5380-5385.

11. Martin E, Miller M, Krebsbach L, Beal JR, Schwartz GG, Sahmoun AE. Serum calcium levels are elevated among women with untreated postmenopausal breast cancer. Cancer Causes Control. 2010;21: 251-257.

12. Palmieri C, MacGregorT, Girgis S, Vigushin D. Serum 25-hydroxyvitamin D levels in early and advanced breast cancer. J Clin Pathol. 2006;59:1334-1336.

13. Mann GB, Kang YC, Brand C, Ebeling PR, Miller JA. Secondary causes of low bone mass in patients with breast cancer: A need for greater vigilance. J Clin Oncol. 2009;27:3605-3610.

14. Ooi LL, Zhou H, Kalak R, et al. Vitamin D deficiency promotes human breast cancer growth in a murine model of bone metastasis. Cancer Res. 2010;70:1835-1844.

15. Ozbey N, Erbil Y, Ademoglu E, Ozarmagan S, Barbaros U, Bozbora A. Correlations between vitamin D status and biochemical/clinical and pathological parameters in primary hyperparathyroidism. World J Surg. 2006;30:321-326.

16. Moosgaard B, Vestergaard P, Heickendorff L, Melsen F, Christiansen P, Mosekilde L. Vitamin D status, seasonal variations, parathyroid adenoma weight and bone mineral density in primary hyperparathyroidism. Clin Endocrinol. 2005;63:506-513.

17. Gissel T, Rejnmark L, Mosekilde L, Vestergaard P. Intake of vitamin D and risk of breast cancer - a meta-analysis. J Steroid Biochem Mol Biol. 2008;111:195-199.

18. Chlebowski RT, Johnson KC, Kooperberg C, et al. Calcium plus vitamin D supplementation and the risk of breast cancer. Natl Cancer Inst. 2008;100:1581-1591.

19. Yetley EA. Assessing the vitamin D status of the US population. Am J Clin Nutr. 2009;88:558-564.

20. Prentice A, Goldberg GR, Schoenmakers I. Vitamin D across the lifecycle: Physiology and biomarkers. Am J Clin Nutr. 2008;88:500-506.

21. Almquist M, Manjer J, Bondeson L, Bondeson AG. Serum calcium and breast cancer risk: Results from a prospective cohort study of 7,847 women. Cancer Causes Control. 2007;18:595-602.

22. Bolland MJ, Grey AB, Gamble GD, Reid IR. Association between primary hyperparathyroidism and increased body weight: A metaanalysis. J Clin Endocrinol Metab. 2005;90:1525-1530.

23. Carmichael AR, Bates T. Obesity and breast cancer: A review of the literature. Breast. 2004;13:85-92.

24. Pal SK, Blazer K, Weitzel J, Somlo G. An association between invasive breast cancer and familial idiopathic hyperparathyroidism: A case series and review of the literature. Breast Cancer Res Treat. 2009;115:1-5.

25. Ghataorhe P, Kurian AW, Pickart A, et al. A carrier of both MEN1 and BRCA2 mutations: Case report and review of the literature. Cancer Genet Cytogenet. 2007;179:89-92.

26. Holmberg E, Wallgren A, Holm LE, Lundell M, Karlsson P. Dose-response relationship for parathyroid adenoma after exposure to ionizing radiation in infancy. Radiat Res. 2002;158:418-423.

27. Eidemuller M, Holmberg E, Jacob P, Lundell M, Karlsson P. Breast cancer risk among Swedish hemangioma patients and possible consequences of radiation-induced genomic instability. Mutat Res. 2009;669:48-55.

\section{Dovepress}

reviews, risk \& safety of medical interventions, epidemiology \& biostatical methods, evaluation of guidelines, translational medicine, health policies \& economic evaluations. The manuscript management system is completely online and includes a very quick and fair peer-review system, which is all easy to use. 